\title{
Choline absorption and evaluation of bioavailability markers when supplementing choline to lactating dairy cows
}

\author{
M. J. de Veth, ${ }^{*} \dagger^{1}$ V. M. Artegoitia, $\ddagger^{2}$ S. R. Campagna,§ H. Lapierre,\# F. Harte,Il and C. L. Girard\# \\ *BioNarus LLC, Cary, NC 27512 \\ †Department of Animal Science, \\ ¥Department of Food Science and Technology, and \\ §Department of Chemistry, University of Tennessee, Knoxville 37996 \\ \#Agriculture and Agri-Food Canada, Sherbrooke, Québec, Canada J1M 0C8 \\ IDepartment of Food Science, Pennsylvania State University, University Park 16802
}

\begin{abstract}
The metabolites of choline have a central role in many mammalian biological processes, and choline supplementation to the periparturient dairy cow improves hepatic lipid metabolism. However, variability in responses to choline supplementation has highlighted a lack of understanding of choline absorption in the lactating dairy cow. Our objective was to determine net choline absorption by measuring net portal fluxes of choline and choline metabolites in cows receiving either dietary supplements of rumen-protected choline (RPC) or abomasal delivery of choline (ADC). We also evaluated markers for choline bioavailability by examining relationships between net portal absorption of choline and choline metabolites in plasma and milk. Five latelactation Holstein cows were used in a $5 \times 5$ Latin square design, with 5 -d treatment periods and a 2 -d interval between periods. Treatments were (1) control ( $0 \mathrm{~g} / \mathrm{d}$ of choline), (2) $12.5 \mathrm{~g} / \mathrm{d}$ of choline fed as RPC, (3) $25 \mathrm{~g} / \mathrm{d}$ of choline fed as RPC, (4) $12.5 \mathrm{~g} / \mathrm{d}$ of choline provided as ADC, and (5) $25 \mathrm{~g} / \mathrm{d}$ of choline provided as ADC. At the end of each 5-d period, milk was sampled and 9 blood samples were collected simultaneously from an artery and portal vein at 30-min intervals. Plasma, milk, and feed ingredient concentrations of acetylcholine, betaine, free choline, glycerophosphocholine, lysophosphatidylcholine, phosphatidylcholine, phosphocholine, and sphingomyelin were quantified by hydrophilic interaction liquid chromatographytandem mass spectrometry. With an increasing dose of $\mathrm{ADC}$, the net portal flux of free choline increased and regression analysis indicated $61 \%$ net absorption
\end{abstract}

\footnotetext{
Received April 29, 2016.

Accepted August 31, 2016.

${ }^{1}$ Corresponding author: mdeveth@bionarus.com

${ }^{2}$ Present address: Department of Animal Science, University of
} Nebraska, Lincoln, NE 68583. of the infused dose. Among the choline metabolites, only concentrations of betaine, free choline, and phosphocholine increased in both arterial plasma $(3.9,1.9$, and 0.4 times, respectively) and milk (2.5, 1.4, and 1.0 times, respectively) with $25 \mathrm{~g} / \mathrm{d}$ of ADC relative to the control. For RPC, the net portal flux of free choline was low relative to $\mathrm{ADC}(13 \%)$, which was similar to the relative difference observed in the concentrations and yields of milk free choline and betaine (averaged 21\%). When evaluating markers for choline bioavailability, betaine was the leading candidate. Betaine in plasma and milk (alone or in combination with phosphocholine) was strongly associated with net free choline portal flux (coefficient of determination ranging from 0.64 to $0.79)$. In summary, free choline supply to the lactating dairy cow increases only specific choline metabolites in plasma and milk, which can be potential markers for choline bioavailability.

Key words: choline, bioavailability, dairy cow, rumen protection

\section{INTRODUCTION}

Choline is an essential nutrient for optimal animal growth and performance and is transformed into various metabolite forms in cells (Figure 1). Phosphatidylcholine (PC), lysophosphatidylcholine (LPC), and sphingomyelin (SM) are lipid-soluble cholinecontaining metabolites that are key constituents of all cell membranes and have a central role in lipid metabolism and cell signaling (Jiang et al., 2014). Free choline (Cho) and choline metabolites, acetylcholine (ACho), betaine (Bet), glycerophosphocholine (GPCho), and phosphocholine (PCho), are water-soluble, with ACho serving as a primary neurotransmitter in the autonomic nervous system (Cheng et al., 1996). Mitochondrial oxidation of Cho forms Bet (Figure 1), which, along with GPCho, acts as organic osmolytes within cells (Eklund et al., 2005; Jiang et al., 2014). Further oxidation of 


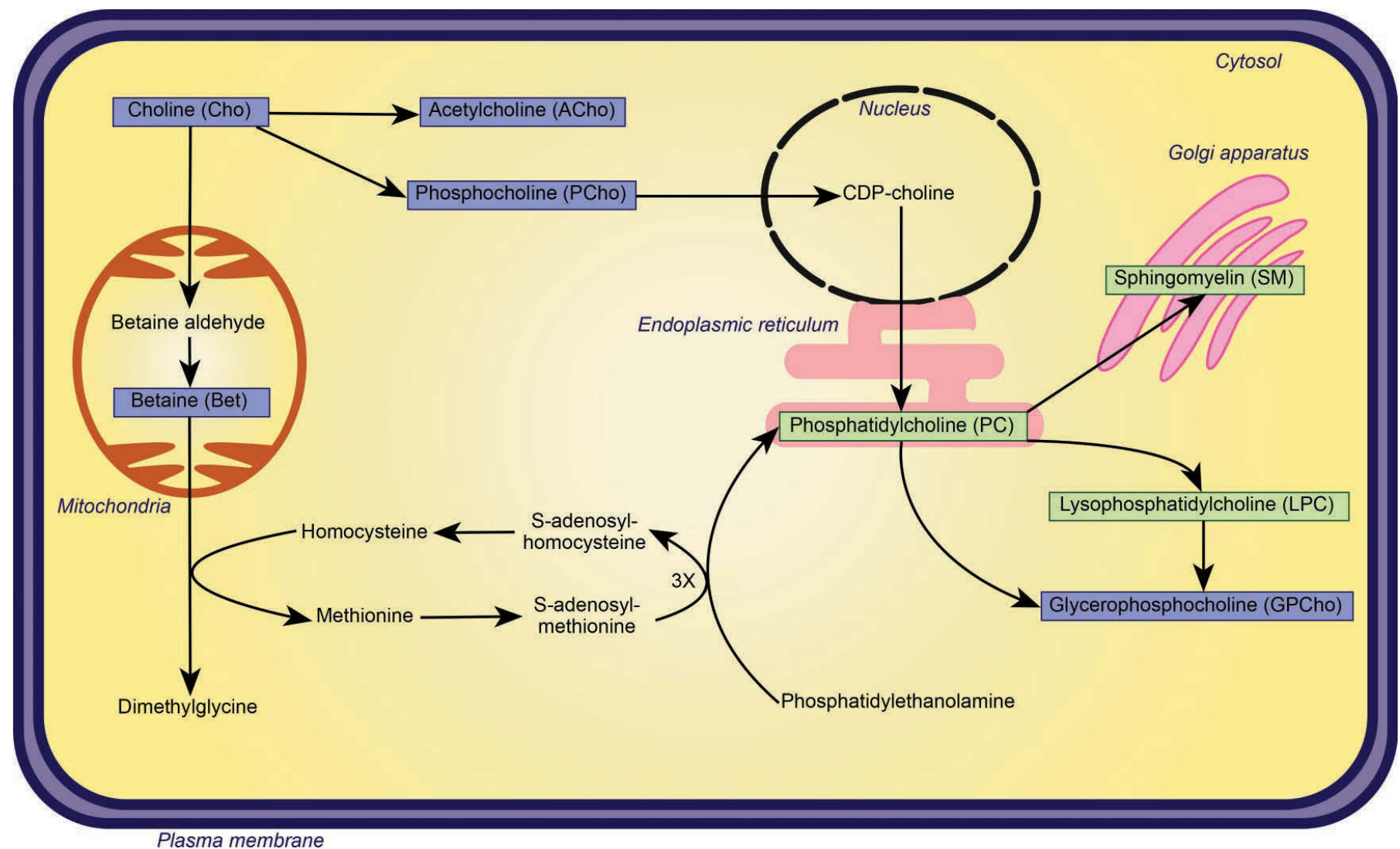

Figure 1. Metabolism of choline in mammalian cells. The site of each reaction is depicted by the location of its end product. The compounds shown in boxes were assayed in plasma and milk in the current experiment. Betaine (Bet), free choline (Cho), acetylcholine (ACho), glycerophosphocholine (GPCho), and phosphocholine (PCho) are all water-soluble, whereas lysophosphatidylcholine (LPC), phosphatidylcholine (PC), sphingomyelin (SM) are lipid-soluble. The PCho and PC are formed from choline via the cytidine diphosphate (CDP) choline pathway in all cells; PC may also be formed by methylating phosphatidylethanolamine in a 3-step process via the phosphatidylethanolamine $N$-methyltransferase pathway. Color version available online.

Bet provides methyl groups for the conversion of homocysteine to methionine, the key step in one carbon metabolism in the cell (Eklund et al., 2005).

The most common clinical sign of choline deficiency across species is fatty liver, which arises from hepatic accumulation of triacylglycerol caused by insufficient PC for the synthesis and secretion of very low density lipoproteins (Jiang et al., 2014). For the dairy cow, the periparturient period is characterized by a high prevalence of moderate to severe fatty liver (Bobe et al., 2004), and supplementation of rumen-protected choline (RPC) was shown to reduce the extent of hepatic triacylglycerol accumulation and increase expression of genes involved in very low density lipoprotein transport (Zom et al., 2011; Goselink et al., 2013). Moreover, recent work with primary bovine hepatocytes reported increased very low density lipoprotein export when incubated with increasing concentrations of choline chloride (CC; McCourt et al., 2015).
Based on the importance of choline, dietary requirements have been established for the major production animals (i.e., poultry, swine, and fish); however, no choline requirement has been established for dairy cattle (NRC, 2001). When reviewing the importance of choline in dairy cattle, the NRC (2001) concluded that a requirement could not be established because of variable responses to choline supplementation in lactating dairy cows and that it would require more extensive feeding experiments than were available at the time of the publication. This variability may be partly explained by a focus on nonspecific biomarkers, such as milk yield and composition, rather than biomarkers related to the metabolic functions of choline. Choline shares many similar attributes to vitamins, for which it is more appropriate to define requirements based on specific biomarkers, such as enzyme activities and tissue concentrations (Combs, 2012). The metabolites of choline are of biological importance in the body, but 
their quantification has been challenging (Phillips, 2012). Previously, only the sum of Cho and the phospholipid forms of choline (i.e., LPC, PC, and SM) in blood (Sharma and Erdman, 1989a; Pinotti et al., 2004) and total choline moiety (TCM) in milk (Deuchler et al., 1998; Pinotti et al., 2003) have been reported for dairy cattle. Recently we described a method based on hydrophilic interaction liquid chromatography-tandem mass spectrometry (HILC-MS/MS) for the quantification in plasma and milk of Cho and the major choline metabolites: ACho, Bet, GPCho, PCho, LPC, SM, and PC (Artegoitia et al., 2014). The application of this method provides opportunity for improved understanding of choline metabolism and its functions, in particular during choline supplementation in dairy cattle.

The variable responses to choline supplementation reported by NRC (2001) may also relate to inconsistent intestinal supply and absorption of choline. The majority of choline in feed ingredients and supplements (e.g., $\mathrm{CC}$ ) are extensively degraded by rumen microorganisms (Sharma and Erdman, 1988, 1989b); therefore, RPC products have been developed to protect choline from degradation in the rumen and delivery to the small intestine for absorption. However, the effectiveness of these RPC products at delivering intestinal absorbable choline, and how their bioavailability compares to unprotected choline that is made available to the intestine, has not been evaluated.

The primary objective of the current experiment was to estimate net choline absorption by measuring the net portal fluxes of Cho and choline metabolites. We compared different doses (12.5 and $25 \mathrm{~g} / \mathrm{d}$ ) of RPC that were fed, representing the practical method of choline supplementation, with unprotected choline delivered abomasally (ADC), representing choline available for absorption. A secondary objective was to evaluate relationships between net portal absorption of Cho and choline metabolites in plasma and milk to assess which markers may be used to estimate bioavailability of RPC products.

\section{MATERIALS AND METHODS}

\section{Ethics Statement}

The experimental protocol was approved by the Institutional Committee for Animal Care at Agriculture and Agri-Food Canada, Sherbrooke Research and Development Centre (Sherbrooke, QC, Canada), and the animals were cared for according to the recommended Code of Practice for the Care and Handling of Dairy Cattle (NFACC, 2009) and the guidelines of the Canadian Council on Animal Care (CCAC, 2009).

\section{Animals and Experimental Design}

Five lactating Holstein cows (206 \pm 25 DIM and averaging $708 \pm 89 \mathrm{~kg}$ of BW, mean $\pm \mathrm{SD}$ ) were used. Cows had been fitted with a rumen cannula and chronic indwelling catheters in the portal and 2 mesenteric veins as well as in a mesenteric artery (Huntington et al., 1989) at least 5 mo before the start of the experiment. The catheters were exteriorized individually over the paralumbar shelf and spine. The right carotid artery was surgically raised to a subcutaneous position to allow access to arterial blood if the catheter placed in a mesenteric artery failed. In cases in which the arterial catheters failed, a catheter was installed in an auricular artery to collect blood.

The cows were randomly assigned to treatments in a $5 \times 5$ Latin square design, with 5 -d treatment periods and a 2-d interval between periods. Treatments were (1) no supplemental choline (control), (2) $12.5 \mathrm{~g} / \mathrm{d}$ of choline fed as RPC (R12.5), (3) $25 \mathrm{~g} / \mathrm{d}$ of choline fed as RPC (R25), (4) $12.5 \mathrm{~g} / \mathrm{d}$ of choline provided as ADC (A12.5), (5) $25 \mathrm{~g} / \mathrm{d}$ of choline provided as ADC (A25). The RPC (ReaShure, Balchem Corporation, New Hampton, NY) was aqueous CC, sprayed on a vegetable carrier and then lipid encapsulated, and contained $21.6 \%$ of the choline ion. The ADC was infused as aqueous CC (CC 70\%, Balchem Corporation) and contained $52.3 \%$ of the choline ion. The choline doses represent the amount of choline ion supplied. To achieve 12.5 and $25 \mathrm{~g} / \mathrm{d}$ of choline ion, 57.9 and 115.9 $\mathrm{g} / \mathrm{d}$ of the ReaShure supplement and 23.9 and $47.8 \mathrm{~g} / \mathrm{d}$ of the CC $70 \%$ supplement were provided, respectively. The 2 doses of choline were selected because $12.5 \mathrm{~g} / \mathrm{d}$ represented the dose of choline that has been supplemented in many of the published research studies and $25 \mathrm{~g} / \mathrm{d}$ would provide greater opportunity to detect changes in bioavailability of choline. The RPC was fed 12 times per day as a top dress, whereas the CC $70 \%$ was dissolved in tap water and infused continuously into the abomasum by way of a peristaltic pump in a daily volume of $6 \mathrm{~L} /$ cow $(260 \mathrm{~mL} / \mathrm{h})$, for the 5 -d treatment period. The infusion device was constructed with a flange to secure abomasal placement (Gressley et al., 2006) and ran through the ruminal cannula and reticular-omasal orifice. The 5-d treatment periods were used to ensure sufficient time to stabilize the flow of choline out of the rumen and subsequent choline absorption and incorporation into milk with RPC feeding. Given the high frequency of feeding and the rumen dynamics of RPC (Elek and Husvéth, 2007) and postrumen absorption and metabolism of choline (Deuchler et al., 1998), we anticipated that absorption and incorporation into milk of choline would be stabilized within $3 \mathrm{~d}$ of feeding RPC. 
Table 1. Ingredient and chemical composition of the $\mathrm{TMR}^{1}$ and estimated $\mathrm{NE}_{\mathrm{I}}$

\begin{tabular}{|c|c|}
\hline Composition & Measurement \\
\hline \multicolumn{2}{|l|}{ Ingredient, $\%$ of $\mathrm{DM}^{2}$} \\
\hline Soybean hulls & 5.8 \\
\hline Corn silage $^{3}$ & 29.9 \\
\hline Grass silage $^{4}$ & 18.2 \\
\hline Corn grain (dry, ground) & 18.1 \\
\hline Canola meal & 21.9 \\
\hline Beet pulp & 2.0 \\
\hline Mineral and vitamin supplement ${ }^{5}$ & 1.8 \\
\hline Calcium carbonate & 0.3 \\
\hline Urea & 0.2 \\
\hline Megalac $^{6}$ & 1.7 \\
\hline \multicolumn{2}{|c|}{ Chemical analysis, \% of DM (unless noted) } \\
\hline $\mathrm{CP}$ & 16.1 \\
\hline Soluble CP & 4.9 \\
\hline $\mathrm{NDF}$ & 35.6 \\
\hline $\mathrm{ADF}$ & 20.6 \\
\hline $\mathrm{NE}_{\mathrm{L}}{ }^{7} \mathrm{Mcal} / \mathrm{kg}$ of $\mathrm{DM}$ & 1.56 \\
\hline $\mathrm{TCM}^{8} \mathrm{mg} / 100 \mathrm{~g}$ & 51.2 \\
\hline
\end{tabular}

${ }^{1}$ All cows were served daily $1 \mathrm{~kg}$ of long grass hay ( $\left.85 \% \mathrm{DM}\right)$ on a DM basis, $10.7 \%$ CP; $3.6 \%$ soluble protein; $31.1 \%$ ADF; $53.6 \%$ NDF.

${ }^{2}$ Dietary DM averaged $50.0 \%$.

${ }^{3}$ On a DM basis, $8.8 \%$ CP; $4.9 \%$ soluble protein; $18.9 \%$ ADF; $36.6 \%$ NDF.

${ }^{4}$ On a DM basis, $17.1 \%$ CP; $6.9 \%$ soluble protein; $29.8 \%$ ADF; $45.6 \%$ NDF.

${ }^{5}$ Contained (per kg) $91.8 \mathrm{~g}$ of Ca; $47.9 \mathrm{~g}$ of P; $47.9 \mathrm{~g}$ of $\mathrm{Mg} ; 11.9 \mathrm{~g}$ of $\mathrm{K} ; 80.8 \mathrm{~g}$ of $\mathrm{Cl} ; 136.8 \mathrm{~g}$ of Na; $15 \mathrm{~g}$ of S; $1,946 \mathrm{mg}$ of Fe; $2,656 \mathrm{mg}$ of $\mathrm{Zn} ; 440 \mathrm{mg}$ of $\mathrm{Cu} ; 1,798 \mathrm{mg}$ of $\mathrm{Mn} ; 23 \mathrm{mg}$ of I; $19.50 \mathrm{mg}$ of Se; 441.6 $\mathrm{kIU}$ of vitamin A; $56.6 \mathrm{kIU}$ of vitamin D; and $2.63 \mathrm{kIU}$ of vitamin $\mathrm{E}$.

${ }^{6}$ Arm \& Hammer Animal Nutrition, Princeton, NJ.

${ }^{7}$ Estimated based on NRC (2001) using actual DMI, milk yield, milk composition, and BW of the cows in the experiment.

${ }^{8}$ Total choline moiety (TCM) is the sum of choline ion originating from free choline, acetylcholine, glycerophosphocholine, phosphocholine, lysophosphatidylcholine, phosphatidylcholine, and sphingomyelin.

Cows were housed in a tiestall barn with free access to water under $17 \mathrm{~h}$ of light per day (0500 to $2200 \mathrm{~h}$ ). To ensure constant intake through the day and com- plete ingestion of the daily allowance, the TMR (Table 1) was served in 12 equal meals per day (2-h intervals) by automatic feeders (Ankom, Fairport, NY) at $95 \%$ of the voluntary feed intake measured the week before the start of the experiment. In addition to the TMR, $1 \mathrm{~kg}$ of long hay was fed every day (as-is basis) to prevent ruminal disturbance. Feed offered and refusals, if present, were weighed and recorded daily. Cows were milked twice daily (0700 and $1900 \mathrm{~h}$ ) and yields at each milking were recorded.

\section{Experimental Samplings}

Feed ingredients were sampled weekly and frozen at $-20^{\circ} \mathrm{C}$ for chemical composition analyses (Table 1) and choline metabolites (Table 2). In each treatment period, milk was sampled at each milking on d 4 and 5 to determine milk composition (DHI agency, Valacta, St-Anne-de Bellevue, QC, Canada). Additionally a composite milk sample, from 2 consecutive milkings (evening and morning) on $\mathrm{d} 5$, was formed based on proportion of daily yield and stored at $-80^{\circ} \mathrm{C}$ for choline metabolite analysis.

On the last day of each 5-d period, para-aminohippurate (pAH; Sigma-Aldrich, St Louis, MO) was infused continuously $(11 \mathrm{~g} / \mathrm{h})$ into a distal mesenteric vein at a rate of $110 \mathrm{~mL} / \mathrm{h}$ using a syringe pump from $30 \mathrm{~min}$ before initiation of blood sampling until end of blood sampling. Blood samples $(\mathrm{n}=9)$ were taken simultaneously from an artery and portal vein catheters every 30 min during 4 consecutive hours starting at the 0900-h meal. Immediately after collection, blood samples were put in Vacutainer tubes with EDTA (Becton Dickinson Inc., Franklin Lakes, NJ); the tubes were then placed on ice until centrifuged $\left(2,000 \times g\right.$ for 10 min at $\left.-4^{\circ} \mathrm{C}\right)$. Plasma was collected and aliquots for choline and pAH analysis were stored at -80 and $-20^{\circ} \mathrm{C}$, respectively.

Table 2. Choline and choline metabolite concentrations $(\mathrm{mg} / 100 \mathrm{~g})$ in feed ingredients used in the diet

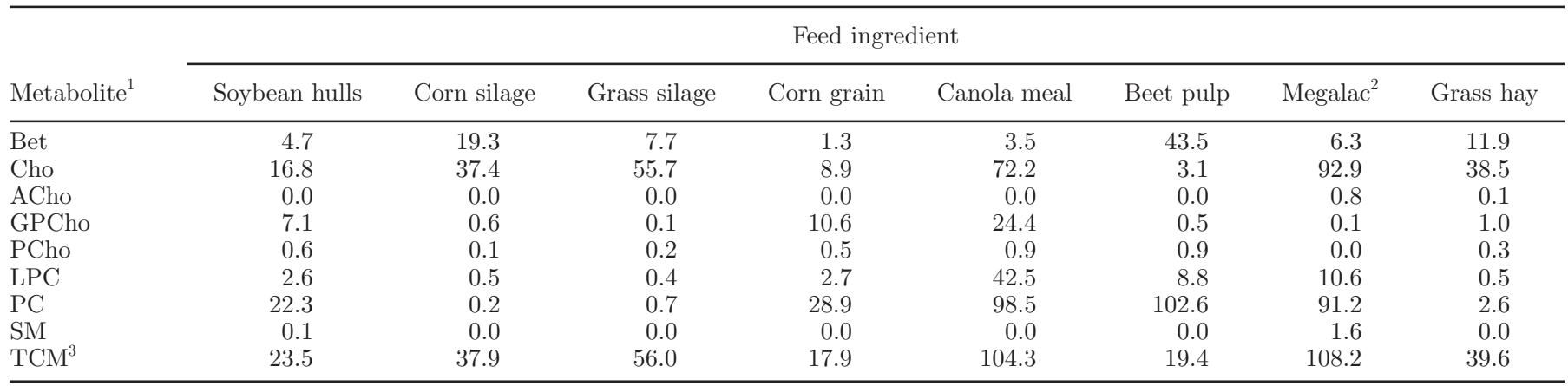

${ }^{1}$ Betaine (Bet), free choline (Cho), acetylcholine (ACho), glycerophosphocholine (GPCho), phosphocholine (PCho), lysophosphatidylcholine (LPC), phosphatidylcholine (PC), sphingomyelin (SM), total choline moiety (TCM).

${ }^{2}$ Arm \& Hammer Animal Nutrition, Princeton, NJ.

${ }^{3}$ Total choline moiety (TCM) is the sum of choline ion originating from Cho, ACho, GPCho, PCho, LPC, PC, and SM. 


\section{Laboratory Analyses}

Feed samples were dried using a forced-air oven at $55^{\circ} \mathrm{C}$ for $48 \mathrm{~h}$, ground with a 1-mm screen, and analyzed by wet chemistry for CP, ADF, and NDF (Agri-Food Laboratories, Guelph, Ontario, Canada). Milk, plasma, and feed choline metabolites were extracted using the method of Bligh and Dyer (1959) and analyzed using HILC-MS/MS based on methods outlined by Zhao et al. (2011) and described by Artegoitia et al. (2014). This method allowed quantification of Bet, Cho, PCho, LPC, PC, and SM in milk, plasma, and feed, as well as ACho and GPCho in milk and feed. Mass spectrometry identified 4 LPC and 16 PC species based on molecular weight information and these were summed to derive total LPC and PC, respectively. The following standards were used: CC trimethyl-d9 (Cho-d9, Cambridge Isotope Laboratories DLM 549-1, Tewksbury, MA), Bet (Bet-d11 Cambridge Isotope Laboratories DLM 407), PCho chloride (PCho-d9, C/D/N Isotopes ICD D-2135, Pointe-Claire, QC, Canada), PC dipalmitoyl (PC-d62, Cambridge Isotope Laboratories DLM 6060.1), SM (SM-d13-C13, Ricerca-Custom Made, Painesville, $\mathrm{OH}$ ), ACho bromide (ACho-d13, C/D/N Isotopes ICN D-1780), and LPC (LPC-d31 Avanti Polar Lipids, 860397, Alabaster, AL). As no commercial internal standard was available for GPCho, a calibration curve was used to calculate the absolute quantitation of GPCho in milk and feed as described by Artegoitia et al. (2014). Analyses were performed on all individual plasma samples. Net portal flux for PC is not reported because, in addition to the summation of $16 \mathrm{PC}$ species to obtain total $\mathrm{PC}$, additional calculations were required to first estimate venoarterial difference and, subsequently, net portal flux, which produced unreliable estimates due to error propagation.

Portal plasma flows were calculated by downstream dilution of pAH (Katz and Bergman, 1969). Concentration of pAH was determined after deacetylation of pAH by heating the samples at $90^{\circ} \mathrm{C}$ for $2 \mathrm{~h}$ in acidic conditions, as described by Lobley et al. (1995).

\section{Calculations and Statistical Analysis}

The molecular weight of each choline metabolite, as well as each species of LPC and PC, were used to calculate the yield of choline metabolites $(\mathrm{g} / \mathrm{d})$ in milk. Net fluxes of Cho and choline metabolites across the portal-drained viscera were calculated by multiplying the venoarterial difference by the corresponding plasma flow. Statistical analyses for arterial concentrations and net fluxes of Cho and choline metabolites were conducted on the average of the 9 sampling times per day. Net portal flux data for 2 cows is missing for a single period, as 1 portal catheter lost patency (R12.5 treatment) and samples were mixed (A25 treatment). Dry matter intake, milk yield, and milk composition variables were averaged for the last $2 \mathrm{~d}$ of each treatment period.

All variables were analyzed using GLIMMIX procedure of SAS (SAS version 9.3, SAS Institute Inc., Cary, $\mathrm{NC}$ ) according to the model

$$
Y_{i j k}=\mu+C_{i}+P_{j}+S_{k}+\varepsilon_{i j k},
$$

where $Y_{i j k}$ indicates the dependent variable, $\mu$ is the overall mean, $C_{i}$ is the effect of the $i$ th cow, $P_{j}$ is the effect of the $j$ th period, $S_{k}$ is the effect of the $k$ th treatment, and $\varepsilon_{i j k}$ is the residual error. Period and choline treatment effects were analyzed as fixed effects and cow as a random effect. Denominator degrees of freedom were calculated using the Kenward-Roger method. All data are presented as least squares means with their respective pooled standard errors. Orthogonal contrasts were conducted using the CONTRAST statement of SAS (SAS Institute Inc., Cary, NC) to determine treatment effects by comparing (1) control versus choline treatments (4 choline treatments combined), (2) RPC versus ADC sources, (3) choline doses of 12.5 versus 25 $\mathrm{g} / \mathrm{d}$, and (4) the interaction between choline source and choline dose.

To estimate net absorption of choline, the relationship between choline dose (i.e., 0, 12.5, and $25 \mathrm{~g} / \mathrm{d}$ ) and net portal Cho flux $(\mathrm{g} / \mathrm{d})$ were assessed for both RPC and ADC with PROC MIXED of SAS. The regression estimates were derived from a direct regression model (Littell et al., 2006):

$$
Y=\beta_{0}+\beta_{L i} x_{j}+\rho_{k}+\delta_{l}+\varepsilon,
$$

where $Y$ indicates the net portal Cho flux, $\beta_{0}$ is the intercept, $\beta_{L i}$ is the linear slope $(L)$ for the $i$ th choline source, $x_{j}$ is the $j$ th dose, $\rho_{k}$ is the kth period, $\delta_{l}$ is the lth cow, and $\varepsilon$ is the residual error. Both period and cow were random effects in the regression model. Assumptions for linearity, equality of intercepts, and equality of the common intercept to the mean for the control $(0 \mathrm{~g} / \mathrm{d})$ were checked with PROC MIXED as described by Littell et al. (1997).

Finally, to examine potential predictors for choline bioavailability, the relationship between net portal flux of Cho versus choline and choline metabolites in milk and plasma were considered with data from cows receiving ADC. Data were only used for ADC-treated animals because they represent the amounts of choline delivered directly to the intestine. Variable selection was performed using the all-possible methods approach and relationships were ranked by coefficient of determi- 
nation $\left(\mathbf{R}^{2}\right)$ using PROC REG. Subsequently, simple and multiple regression analysis were conducted using PROC REG to assess the relationship between selected variables with high $\mathrm{R}^{2}$. For the identified best regression models, the RPC treatments were used to assess the predictive ability of the models by calculating the root mean squared prediction errors.

\section{RESULTS}

\section{Intake, Milk Production, and Milk Composition}

As shown in Table 3, DMI, milk yield, and SCC were unaltered by choline treatment $(P>0.20)$. In addition, fat, CP, and lactose content and yield in milk were not affected by choline treatment $(P>0.20)$. As the experimental design used short treatment periods, restricted intake, and cows in late lactation, it was unlikely that differences in milk production variables would be observed.

\section{Arterial Concentrations of Choline and Choline Metabolites}

Arterial plasma concentrations of Bet, Cho, PCho, and LPC were all increased by choline treatment (Table $4)$. We noted a choline source by dose interaction for arterial plasma Bet and Cho concentrations $(P=0.007$ and 0.02 , respectively), with the increase in concentration only observed with ADC. The increase in arterial plasma PCho concentration occurred in a dose-dependent manner $(P=0.02)$ and was greater with ADC than with $\operatorname{RPC}(P=0.02)$. Although arterial plasma LPC concentration increased with choline treatment, no differences were observed between the sources and doses of choline (Table 4). Arterial plasma PC, SM, and total choline (sum of Cho, PCho, LPC, PC, and SM) concentrations were not altered by choline treatment $(P \geq 0.57)$, although SM concentration was higher at 25 versus $12.5 \mathrm{~g} / \mathrm{d}$.

\section{Plasma Flow and Net Flux of Choline and Choline Metabolites}

The portal plasma flow was not affected by choline treatments (Table 4). The net portal flux of Cho had a choline source effect $(P<0.001)$, and this occurred in a dose-dependent manner $(P=0.02)$. The regression between the choline dose, for each of the 2 choline sources, and net portal flux of Cho (g/d) had an intercept of 2.97 and slopes of 0.08 and 0.61 for RPC and ADC, respectively (Figure 2). The intercept (95\% CI of -0.06 to 5.99) indicates the net portal flux of Cho when choline is not supplemented. The RPC and ADC slopes had $95 \%$ confidence intervals of -0.14 to 0.29 and 0.39 to 0.83 , respectively. The slopes indicate the net proportions of choline consumed as RPC or ADC that appeared in the portal blood. When comparing the RPC slope to the ADC slope, the relative bioavailability of RPC was $13 \%$. We found a choline source by dose interaction for net portal flux of LPC $(P=0.03)$ that was a result of the negative flux observed only with the R12.5 treatment (Table 4), with LPC flux not different from zero for all other treatments $(P>0.40)$.

Table 3. Intake and milk production when lactating dairy cows were provided different sources and doses of choline ${ }^{1}$

\begin{tabular}{|c|c|c|c|c|c|c|c|c|c|c|}
\hline \multirow[b]{2}{*}{ Item } & \multicolumn{5}{|c|}{ Treatment } & \multirow[b]{2}{*}{ SEM } & \multicolumn{4}{|c|}{$P$-value } \\
\hline & Control & $\mathrm{R} 12.5$ & $\mathrm{R} 25$ & $\mathrm{~A} 12.5$ & $\mathrm{~A} 25$ & & $\operatorname{Trt}^{2}$ & Source $^{3}$ & Dose $^{4}$ & Source $\times$ dose $^{5}$ \\
\hline DMI, kg/d & 21.1 & 21.7 & 21.3 & 20.3 & 20.6 & 1.2 & 0.87 & 0.19 & 0.96 & 0.68 \\
\hline $\begin{array}{l}\text { Milk yield, } \mathrm{kg} / \mathrm{d} \\
\text { Milk fat }\end{array}$ & 31.3 & 32.0 & 31.9 & 31.2 & 32.4 & 1.2 & 0.69 & 0.90 & 0.67 & 0.58 \\
\hline$\%$ & 4.04 & 4.03 & 4.04 & 3.99 & 3.96 & 0.07 & 0.46 & 0.22 & 0.84 & 0.66 \\
\hline $\begin{array}{l}\mathrm{g} / \mathrm{d} \\
\text { Milk CP }\end{array}$ & 1,267 & 1,288 & 1,287 & 1,248 & 1,282 & 43 & 0.84 & 0.57 & 0.69 & 0.66 \\
\hline $\begin{array}{l}\% \\
\mathrm{~g} / \mathrm{d}\end{array}$ & $\begin{array}{l}3.46 \\
1,084^{-}\end{array}$ & $\begin{array}{l}3.47 \\
1,108\end{array}$ & $\begin{array}{l}3.42 \\
1,089\end{array}$ & $\begin{array}{l}3.40 \\
1,066\end{array}$ & $\begin{array}{l}3.39 \\
1,094\end{array}$ & $\begin{array}{l}0.10 \\
49\end{array}$ & $\begin{array}{l}0.21 \\
0.91\end{array}$ & $\begin{array}{l}0.09 \\
0.67\end{array}$ & $\begin{array}{l}0.25 \\
0.91\end{array}$ & $\begin{array}{l}0.58 \\
0.59\end{array}$ \\
\hline Milk lactose & & & & & & & & & & \\
\hline $\begin{array}{l}\% \\
\mathrm{~g} / \mathrm{d}\end{array}$ & $\begin{array}{c}4.57 \\
1,433\end{array}$ & $\begin{array}{l}4.58 \\
1,468 \\
57\end{array}$ & $\begin{array}{l}4.59 \\
1,460 \\
56\end{array}$ & $\begin{aligned} & 4.53 \\
1,413 & \\
58 & \end{aligned}$ & $\begin{array}{l}4.55 \\
1,473 \\
45\end{array}$ & $\begin{array}{l}0.07 \\
54\end{array}$ & $\begin{array}{l}0.85 \\
0.71 \\
0.23\end{array}$ & $\begin{array}{l}0.18 \\
0.68 \\
0.51\end{array}$ & $\begin{array}{l}0.63 \\
0.60 \\
0.35\end{array}$ & $\begin{array}{l}0.81 \\
0.50 \\
0.49\end{array}$ \\
\hline
\end{tabular}

\footnotetext{
${ }^{1}$ Treatments were: Control, no supplemental choline; R12.5, $12.5 \mathrm{~g} / \mathrm{d}$ of choline fed as rumen-protected choline; R25, $25 \mathrm{~g} / \mathrm{d}$ of choline fed as rumen-protected choline; A12.5, $12.5 \mathrm{~g} / \mathrm{d}$ of choline abomasally delivered as unprotected choline; A25, $25 \mathrm{~g} / \mathrm{d}$ of choline abomasally delivered as unprotected choline.

${ }^{2}$ Effect of treatment (Trt), control vs. all choline treatments.

${ }^{3}$ Effect of choline source, rumen-protected vs abomasal infusion.

${ }^{4}$ Effect of choline dose, 12.5 vs. $25 \mathrm{~g} / \mathrm{d}$.

${ }^{5}$ Interaction of choline source $\times$ dose.
} 
Table 4. Arterial plasma concentration and net portal flux of choline and choline metabolites when lactating dairy cows were provided different sources and doses of choline ${ }^{1}$

\begin{tabular}{|c|c|c|c|c|c|c|c|c|c|c|}
\hline \multirow[b]{2}{*}{ Metabolite $^{2}$} & \multicolumn{5}{|c|}{ Treatment } & \multirow[b]{2}{*}{ SEM } & \multicolumn{4}{|c|}{$P$-value } \\
\hline & Control & $\mathrm{R} 12.5$ & $\mathrm{R} 25$ & $\mathrm{~A} 12.5$ & $\mathrm{~A} 25$ & & $\operatorname{Trt}^{3}$ & Source $^{4}$ & $\operatorname{Dose}^{5}$ & Source $\times \operatorname{dose}^{6}$ \\
\hline \multicolumn{11}{|c|}{ Arterial plasma concentration, $\mu M$} \\
\hline Bet & 30.6 & 42.6 & 36.2 & 102.7 & 151.2 & 9.1 & $<0.001$ & $<0.001$ & 0.03 & 0.007 \\
\hline Cho & 4.54 & 4.85 & 5.34 & 7.58 & 13.09 & 0.95 & 0.009 & $<0.001$ & 0.006 & 0.02 \\
\hline PCho & 3.47 & 3.81 & 4.08 & 4.21 & 4.96 & 0.36 & 0.003 & 0.02 & 0.02 & 0.25 \\
\hline LPC & 157 & 215 & 209 & 189 & 180 & 16 & 0.03 & 0.11 & 0.66 & 0.92 \\
\hline $\mathrm{PC}$ & 8,780 & 9,246 & 9,844 & 8,496 & 7,315 & 909 & 0.95 & 0.06 & 0.71 & 0.27 \\
\hline SM & 252 & 242 & 281 & 250 & 266 & 18 & 0.57 & 0.79 & 0.05 & 0.37 \\
\hline $\mathrm{TC}^{7}$ & 9,197 & 9,712 & 10,344 & 8,948 & 7,780 & 924 & 0.99 & 0.06 & 0.74 & 0.27 \\
\hline \multicolumn{11}{|c|}{ Plasma flow ${ }^{8} \mathrm{~L} / \mathrm{h}$} \\
\hline \multirow{2}{*}{\multicolumn{11}{|c|}{ Net portal flux, ${ }^{8} \mathrm{mmol} / \mathrm{h}$}} \\
\hline & & & & & & & & & & \\
\hline Bet & 0.0 & -3.0 & 0.3 & -0.7 & -2.2 & 2.1 & 0.54 & 0.96 & 0.68 & 0.29 \\
\hline Cho & 1.7 & 1.3 & 2.2 & 4.0 & 7.1 & 0.8 & 0.05 & $<0.001$ & 0.02 & 0.18 \\
\hline PCho & -0.1 & 0.4 & 0.0 & 0.0 & -0.1 & 0.2 & 0.42 & 0.32 & 0.22 & 0.42 \\
\hline LPC & 6.8 & -27.2 & 3.7 & 2.8 & -7.7 & 9.1 & 0.15 & 0.30 & 0.26 & 0.03 \\
\hline $\mathrm{SM}$ & -4.9 & -15.9 & -14.3 & -8.7 & -7.4 & 12.2 & 0.53 & 0.50 & 0.89 & 0.99 \\
\hline
\end{tabular}

${ }^{1}$ Treatments were: Control, no supplemental choline; R12.5, $12.5 \mathrm{~g} / \mathrm{d}$ of choline fed as rumen-protected choline; R25, $25 \mathrm{~g} / \mathrm{d}$ of choline fed as rumen-protected choline; A12.5, 12.5 $\mathrm{g} / \mathrm{d}$ of choline abomasally delivered as unprotected choline; A25, $25 \mathrm{~g} / \mathrm{d}$ of choline abomasally delivered as unprotected choline.

${ }^{2}$ Betaine (Bet), free choline (Cho), phosphocholine (PCho), lysophosphatidylcholine (LPC), phosphatidylcholine (PC), sphingomyelin (SM), total choline (TC).

${ }^{3}$ Effect of treatment (Trt), control vs. all choline treatments.

${ }^{4}$ Effect of choline source, rumen-protected vs. abomasal infusion.

${ }^{5}$ Effect of choline dose, 12.5 vs. $25 \mathrm{~g} / \mathrm{d}$.

${ }^{6}$ Interaction of choline source $\times$ dose.

${ }^{7}$ Total choline (TC) is the sum of Cho, PCho, LPC, PC, and SM.

${ }^{8}$ One missing observation each for R12.5 and A25 treatments (i.e., $\mathrm{n}=4$ ). 


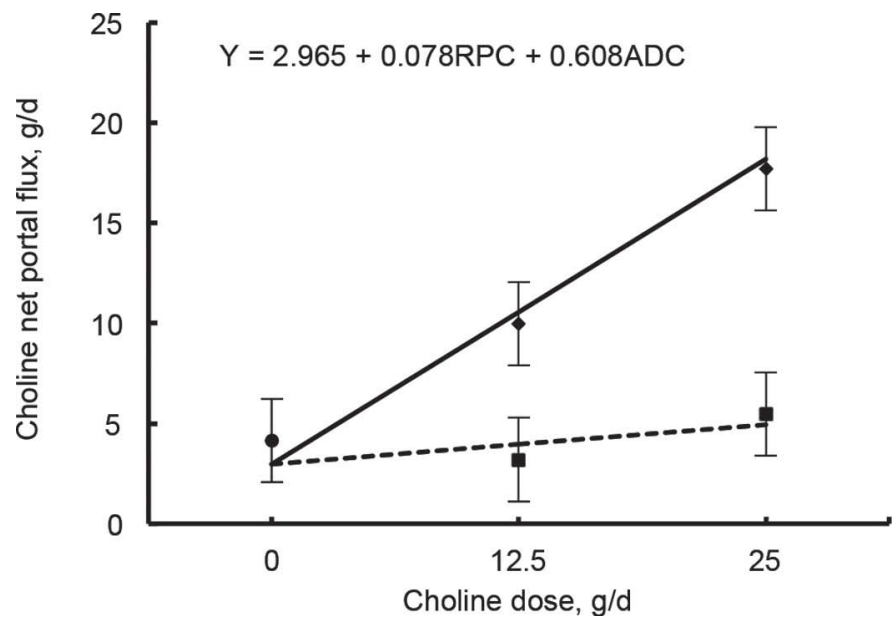

Figure 2. Relationship between free choline net portal flux and dose of choline fed as rumen-protected choline (RPC; ---) or as unprotected choline delivered abomasally $(\mathrm{ADC} ;-)$ in lactating dairy cows. Points depict LSM for control (no choline supplemented; $\bullet$ ), RPC (ם) and $\operatorname{ADC}(\checkmark)$. The slope estimates for RPC $(P=0.46, \mathrm{SE}=0.102)$ and $\operatorname{ADC}(P<0.001, \mathrm{SE}=0.105)$ were obtained by fitting the individual cow data; $\mathrm{Y}=$ free choline net portal flux $(\mathrm{g} / \mathrm{d})$.

Net portal fluxes for all of the other choline metabolites were not altered by choline treatment $(P \geq 0.42)$.

\section{Concentrations and Yields of Milk Choline and Choline Metabolites}

Milk concentrations of Bet, Cho, and total choline (sum of Cho, ACho, GPCho, PCho, LPC, PC, and SM) were increased by choline treatments (Table 5). Milk Bet and total choline concentrations increased in a dose-dependent manner $(P=0.02$ and 0.01 , respectively), with 4.5 and 4.7 times greater increases, respectively, for $\mathrm{ADC}$ relative to $\mathrm{RPC}$ at $25 \mathrm{~g} / \mathrm{d}$. A dose effect was not detected for milk Cho concentration $(P=0.06)$, with the increase 3.9 times greater for ADC than for RPC on average across the 2 doses. We found a choline source effect for milk concentrations of ACho and PCho $(P=0.01$ and 0.02 , respectively), which was due to a greater increase with ADC. Milk yield of Bet also increased in a dose-dependent manner $(P=$ 0.02 ) for choline treatments (Table 5), with a 4.1 times greater increase for ADC relative to RPC at $25 \mathrm{~g} / \mathrm{d}$. With milk Cho yield, as for concentration, we found no dose effect $(P=0.08)$, with a 3.9 times greater increase for ADC than for RPC on average across the 2 doses. Likewise a choline source effect was observed for milk yields of ACho, PCho, and TCM $(P=0.03,0.02$ and 0.04, respectively), which increased with ADC relative to RPC supplementation.

\section{Predictors of Choline Bioavailability}

When examining the relationships between net portal flux of Cho (independent variable) and choline metabolites in milk and plasma (dependent variables), with data from cows receiving ADC, several potential predictors were identified that could be used for future choline bioavailability studies (Table 6). Two of the best predictors of the net portal flux of Cho were the combination of Bet and PCho concentrations in arterial plasma $\left(\mathrm{R}^{2}=0.79\right)$ and in milk $\left(\mathrm{R}^{2}=0.74\right)$. Arterial plasma Bet and Cho, as well as milk Bet concentration, each had a strong association with the net portal flux of Cho (Table 6). When using the RPC treatment results to evaluate the relationships presented in Table 5, the root mean squared prediction errors were smaller than the root mean square error derived from fitting the regression to the model-building data set. This indicates that for each equation the root mean square error gives an appropriate indication of the predictive ability of the equation.

\section{DISCUSSION}

The first objective of the present experiment was to examine net choline absorption in the lactating dairy cow, knowing exactly the rate of choline reaching the abomasum through ADC or when fed as RPC, by measuring the flux of Cho across the portal-drained viscera. Although the supplementation of RPC to periparturient dairy cows reverses a basic choline deficiency by reducing hepatic triacylglycerol accumulation (Zom et al., 2011; Elek et al., 2013), little is known about the absorption of choline in the dairy cow. Therefore, improving the understanding of choline absorption, and how it changes with choline supplementation, are key steps in establishing the choline requirements of the dairy cow.

The absorption of choline metabolites at the small intestine occurs through independent processes (Cheng et al., 1996). In the case of Cho, it is absorbed by carrier-mediated transport that is saturable and substrate-specific at low concentrations and by passive diffusion at high concentrations (Sheard and Zeisel, 1986). Within the enterocyte, Cho will cross the basolateral membrane and enter the hepatic portal venous system (Cheng et al., 1996; Jiang et al., 2014). In the present experiment, we supplied choline in the form of $\mathrm{CC}$, as this compound readily disassociates in water to form Cho (OECD, 2004). The slope of the linear regression for net portal Cho flux relative to ADC dose indicates that the net intestinal absorption of ADC was $61 \%$ (95\% CI from 39 to 83\%). This value, representing 
Table 5. Concentration and yield of choline and choline metabolites in milk when lactating dairy cows were provided different sources and dose of choline

\begin{tabular}{|c|c|c|c|c|c|c|c|c|c|c|}
\hline \multirow[b]{2}{*}{ Metabolite $^{2}$} & \multicolumn{5}{|c|}{ Treatments } & \multirow[b]{2}{*}{ SEM } & \multicolumn{4}{|c|}{$P$-value } \\
\hline & Control & $\mathrm{R} 12.5$ & $\mathrm{R} 25$ & A12.5 & $\mathrm{A} 25$ & & $\operatorname{Trt}^{3}$ & Source $^{4}$ & $\operatorname{Dose}^{5}$ & Source $\times \operatorname{dose}^{6}$ \\
\hline \multicolumn{11}{|c|}{ Concentration, $\mu M$} \\
\hline Bet & 38.9 & 42.3 & 60.7 & 100.1 & 137.2 & 13.2 & 0.002 & $<0.001$ & 0.02 & 0.38 \\
\hline Cho & 160 & 189 & 223 & 279 & 388 & 40 & 0.01 & 0.003 & 0.06 & 0.30 \\
\hline ACho & 3.20 & 3.15 & 3.55 & 4.01 & 4.32 & 0.29 & 0.09 & 0.01 & 0.22 & 0.87 \\
\hline GPCho & 117 & 140 & 130 & 163 & 129 & 27 & 0.06 & 0.33 & 0.06 & 0.27 \\
\hline PCho & 54.8 & 41.2 & 59.1 & 62.5 & 106.9 & 25.7 & 0.41 & 0.02 & 0.03 & 0.33 \\
\hline LPC & 6.36 & 5.96 & 7.29 & 6.56 & 7.12 & 0.79 & 0.67 & 0.79 & 0.25 & 0.63 \\
\hline $\mathrm{PC}$ & 697 & 669 & 677 & 654 & 698 & 40 & 0.54 & 0.93 & 0.43 & 0.58 \\
\hline SM & 40.9 & 39.6 & 42.0 & 37.0 & 38.4 & 2.7 & 0.39 & 0.09 & 0.29 & 0.79 \\
\hline $\mathrm{TC}^{7}$ & 1,079 & 1,088 & 1,142 & 1,219 & 1,371 & 44 & 0.004 & $<0.001$ & 0.01 & 0.16 \\
\hline \multicolumn{11}{|l|}{ Yield, g/d } \\
\hline Bet & 0.14 & 0.16 & 0.23 & 0.37 & 0.51 & 0.05 & 0.002 & $<0.001$ & 0.02 & 0.41 \\
\hline Cho & 0.53 & 0.63 & 0.72 & 0.91 & 1.30 & 0.15 & 0.01 & 0.005 & 0.08 & 0.26 \\
\hline ACho & 0.014 & 0.015 & 0.016 & 0.019 & 0.020 & 0.002 & 0.12 & 0.03 & 0.32 & 0.98 \\
\hline GPCho & 0.94 & 1.17 & 0.99 & 1.30 & 1.05 & 0.21 & 0.09 & 0.31 & 0.04 & 0.69 \\
\hline PCho & 0.34 & 0.24 & 0.33 & 0.36 & 0.60 & 0.15 & 0.65 & 0.02 & 0.05 & 0.31 \\
\hline LPC & 0.10 & 0.10 & 0.12 & 0.11 & 0.12 & 0.02 & 0.72 & 0.71 & 0.38 & 0.83 \\
\hline $\mathrm{PC}$ & 16.7 & 16.4 & 16.9 & 15.7 & 17.1 & 1.2 & 0.91 & 0.84 & 0.43 & 0.68 \\
\hline $\mathrm{SM}$ & 0.91 & 0.89 & 0.92 & 0.82 & 0.87 & 0.08 & 0.62 & 0.35 & 0.53 & 0.87 \\
\hline $\mathrm{TCM}^{8}$ & 3.76 & 3.90 & 4.05 & 4.20 & 4.98 & 0.27 & 0.11 & 0.04 & 0.12 & 0.28 \\
\hline
\end{tabular}

${ }^{1}$ Treatments were: Control, no supplemental choline; R12.5, $12.5 \mathrm{~g} / \mathrm{d}$ of choline fed as rumen-protected choline; R25, $25 \mathrm{~g} / \mathrm{d}$ of choline fed as rumen-protected choline; A12.5, 12.5 $\mathrm{g} / \mathrm{d}$ of choline abomasally delivered as unprotected choline; A25, $25 \mathrm{~g} / \mathrm{d}$ of choline abomasally delivered as unprotected choline.

${ }^{2}$ Betaine (Bet), free choline (Cho), acetylcholine (ACho), glycerophosphocholine (GPCho), phosphocholine (PCho), lysophosphatidylcholine (LPC), phosphatidylcholine (PC), sphingomyelin (SM), total choline (TC), total choline moiety (TCM).

${ }^{3}$ Effect of treatment (Trt), control vs. all choline treatments.

${ }^{4}$ Effect of choline source, rumen-protected vs. postruminal infusion.

${ }^{5}$ Effect of choline dose, 12.5 vs. $25 \mathrm{~g} / \mathrm{d}$.

${ }^{6}$ Interaction of choline source $\times$ dose.

${ }^{7}$ Total choline (TC) is the sum of Cho, ACho, GPCho, PCho, LPC, PC, and SM.

${ }^{8}$ Total choline moiety (TCM) is the sum of choline ion originating from Cho, ACho, GPCho, PCho, LPC, PC, and SM. 
recovery in the portal vein of $\mathrm{ADC}$, may underestimate true absorption, as it does not take into account any absorbed Cho that was retained or metabolized by the whole gastrointestinal wall, either from lumen or arterial supply. We are not aware of any previous studies that have quantified absorption of $\mathrm{CC}$ in ruminants. In 30-d-old broiler chicks, Budowski et al. (1977) reported $80.6 \%$ apparent choline absorbability when the diet contained $0.1 \%$ CC. This estimate of absorption was based on the disappearance of choline from the lumen of the intestine and, therefore, is likely to overestimate choline absorption relative to our own estimate, as the estimate in the broiler study does not account for choline metabolism or retention by the intestine during absorption. Moreover, disappearance of choline from the lumen of the intestine does not take into account microbial conversion of choline to trimethylamine that may occur in the gut lumen in the broiler (March and MacMillan, 1980). Results from studies with different animal models, which have considered choline uptake and transfer across the intestine using radiolabeled CC, suggest that it is possible part of the Cho absorbed from the intestinal lumen is metabolized and retained within the enterocyte. Sheard and Zeisel (1986) reported that 15 to $21 \%$ of Cho taken up by the rat intestine in vitro was metabolized to other choline forms, and Kettunen et al. (2001) observed that $25 \%$ of the radioactivity was retained in the jejunum of 28-d-old broiler chicks. Likewise, Flower et al. (1972) studied the metabolism and transfer of radiolabeled CC across the hamster intestine and found that $30 \%$ of the Cho absorbed was metabolized and retained as Bet in the intestinal wall. Betaine retention in cells exerts an osmoprotective effect, and evidence suggests Bet supports intestinal growth and function (Eklund et al., 2005). Based on studies in other animal models, it is possible that a portion of ADC, not accounted for in our estimate of bioavailability, is metabolized and retained at the intestine of the lactating dairy cow. Furthermore, other parts of the gastrointestinal wall may have metabolized Cho supplied from arterial blood, and this metabolism would have also reduced the measured net portal absorption.

Along with estimating net choline absorption with $\mathrm{ADC}$, we aimed to estimate absorption with a RPC product that provides choline in a form that can be practically applied on farms and has been reported to induce positive effects on milk production and animal health when supplemented in early lactation (Zahra et al., 2006; Zom et al., 2011; Lima et al., 2012). We observed that the net portal flux of Cho was less for RPC than for ADC. In addition, the bioavailability of RPC was low, which is supported by a relative bioavailability of $13 \%$ when comparing the slope-ratio of the regression lines for RPC and ADC (Figure 2). Similarly, although we did observe an increase in the concentrations and yields of Cho and Bet in milk attributed to both choline sources, the relative increase averaged only $21 \%$ for RPC compared with ADC. The bioavailability of RPC may be underestimated, because the measure of net absorption does not account for any absorbed Cho that was retained or metabolized by the whole gastrointestinal wall. The low bioavailability of RPC may relate partly to the practical challenge of delivering choline for absorption in the ruminant. The choline form that is incorporated within RPC is CC, which is very hygroscopic and makes it more difficult to protect choline from degradation in the rumen compared with compounds such as Met. As a result, RPC products tend to contain more lipid than rumen-protected Met to minimize choline release in the rumen due to the attraction of water. Postruminal release of an active compound for absorption is generally inversely related to the degree of rumen protection (Papas and $\mathrm{Wu}, 1997$ ); thus, the need to use more lipid coating to protect choline may adversely affect its overall bioavailability.

Table 6. Relationships between net portal flux of free choline (NPF_Cho; g/d) and concentration $(\mu M)$ of choline metabolites in arterial plasma and milk of lactating dairy cows receiving $0,12.5$, and $25 \mathrm{~g} / \mathrm{d}$ of choline abomasally delivered as choline chloride ${ }^{1}$

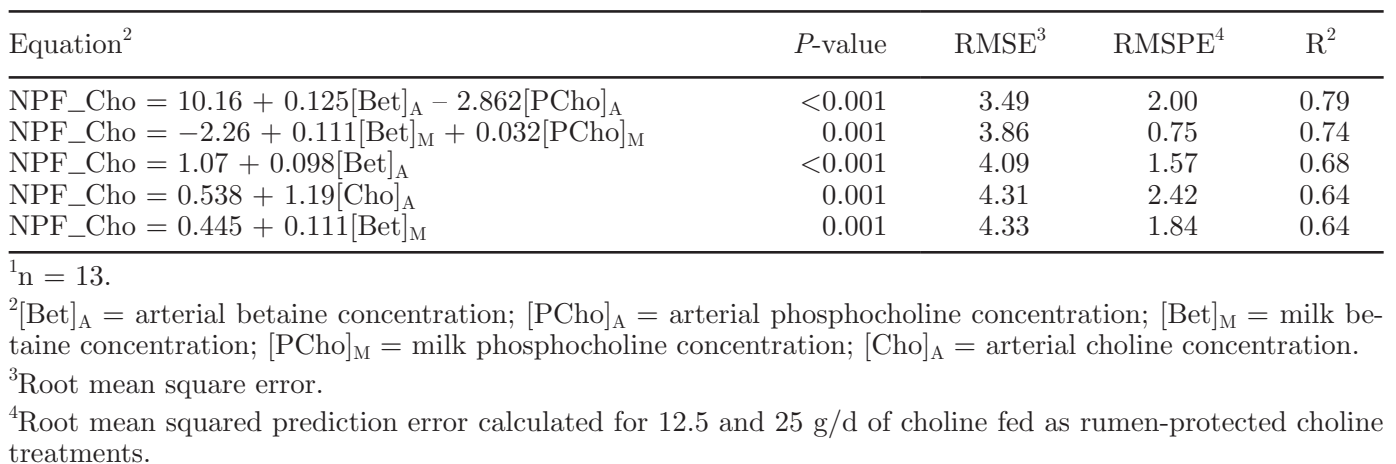


Hepatic accumulation of triacylglycerol is the classic clinical sign of choline deficiency across all species (Jiang et al., 2014). Initial studies with RPC supplementation during the periparturient period found no effects of choline supplementation (6 to $14 \mathrm{~g} / \mathrm{d}$ of choline ion) on liver triacylglycerol concentrations (Hartwell et al., 2000; Piepenbrink and Overton, 2003; Zahra et al., 2006). More recently, Zom et al. (2011) reported that liver triacylglycerol concentrations were reduced by a third during the first 6 wk of lactation when supplementing RPC at a dose similar to the low dose of RPC used in the current experiment. Based on the bioavailability we obtained for the same RPC product, this reduction in liver triacylglycerol concentrations reported by Zom et al. (2011) would have been achieved by providing $1.1 \mathrm{~g} / \mathrm{d}$ of net absorbed Cho from the RPC product. The low choline net absorption we observed for RPC, compared with ADC, suggests that higher doses of choline than those that are fed in practice (i.e., $>12.5 \mathrm{~g} / \mathrm{d}$ of choline ion) have the potential to improve further the hepatic response. A recent study supplementing 18.7 and $37.3 \mathrm{~g} / \mathrm{d}$ of choline ion as RPC at pre- and postpartum, respectively, resulted a $66 \%$ reduction in liver triacylglycerol concentrations at 7 DIM (Elek et al., 2013). Therefore, the dose of choline supplied by RPC will be an important consideration for future research focused on establishing requirements and allowances of choline for dairy cows.

Limited data exist on the effect of choline supplementation on blood and milk choline metabolite concentrations. With increasing doses of ADC in the present experiment, Cho, Bet, and PCho arterial plasma and milk concentrations increased, but no change occurred in PC and SM concentrations. Similarly in breastfeeding women, supplementation of $750 \mathrm{mg} / \mathrm{d}$ of PC increased plasma and milk concentrations of Cho, Bet, and PCho, but had no effect on PC and SM concentrations (Fischer et al., 2010). Previous studies that have reported concentrations of choline in plasma and milk after supplementing choline to lactating dairy cows have used analytical methods that did not identify individual choline metabolites. Using methodology that grouped Cho, LPC, PC, and SM together as one value, plasma concentrations were unchanged when lactating dairy cows received abomasal infusion of CC and RPC (Sharma and Erdman, 1989a; Pinotti et al., 2004). In the current experiment, despite observing increases in Cho, Bet, and PCho with ADC dose, we observed no effect of choline supplementation on arterial total choline concentration. This suggests that the changes in individual water-soluble choline metabolites in plasma that occur with choline supplementation maybe be masked when they are grouped with the lipid-soluble choline metabolites.
The milk concentration and yield of total choline in the present experiment control group $(1,079 \mu M$ and $3.79 \mathrm{~g} / \mathrm{d}$, respectively) were similar to those reported previously for cows at the same stage of lactation (Artegoitia et al., 2014; $944 \mu M$ and $3.34 \mathrm{~g} / \mathrm{d}$, respectively). The increase in TCM yield with ADC observed in the present experiment represented 3.5 and $4.6 \%$ of the choline ion provided with A12.5 and A25, respectively. These proportions are consistent with that reported by Deuchler et al. (1998) when mid-lactation dairy cows received 0 to $75 \mathrm{~g} / \mathrm{d}$ of $\mathrm{CC}$ as ADC (average of $3.7 \%$ ) when discounting the chloride ion in calculating the choline dose. Deuchler et al. (1998) also supplemented $50 \mathrm{~g} / \mathrm{d}$ of CC as RPC and reported an increase in TCM yield in milk relative to choline ion dose $(1.3 \%)$ that was approximately one-third of that observed with ADC, which is similar to the proportion we found when comparing RPC versus ADC in the current experiment (1.1 vs. $4.1 \%$, respectively). Using the same analytical method applied by Deuchler et al. (1998) to measure choline, Pinotti et al. (2003) found a 8.6\% increase in TCM yield in milk relative to choline dose when supplemented at $20 \mathrm{~g} / \mathrm{d}$ of CC as RPC from -14 to 30 DIM, when discounting the chloride ion in calculating choline dose. This relative increase in TCM yield is approximately 2 times greater than that observed even with $\mathrm{ADC}$ in the current experiment and by Deuchler et al. (1998), which may indicate differences in absorption or metabolism of choline when supplemented at different stages of lactation.

A second objective of the current experiment was to evaluate the relationships between Cho net portal flux and choline metabolites in plasma and milk for cows receiving ADC to assess the future suitability of using markers for determining bioavailability of RPC products. Bioavailability is the degree to which an administered nutrient or compound is absorbed in a form that can be used in metabolism (e.g., in plasma) or within normal metabolic processes (e.g., in milk synthesis) in an animal (Ammerman et al., 1995). As described earlier, lactating dairy cows studies that have reported choline in blood or milk when supplementing choline have measured the sum of several choline metabolites. Deuchler et al. (1998) considering milk TCM a qualitative indicator of choline bioavailability, reporting a dose-dependent increase in dairy cows receiving graded amounts of abomasally infused CC $(0,25,50$, and 75 g/d). However, Deuchler et al. (1998) concluded that milk choline was not suitable for quantitative evaluation of choline bioavailability and suggested future research should consider milk Bet secretion as a choline bioavailability indicator.

With the analytical methodology adopted in the current experiment we were able to evaluate whether 
specific choline metabolites, either alone or combined, could be used as biomarkers for choline bioavailability. We hypothesized that individual metabolites would be more sensitive markers of choline bioavailability. The variable selection and regression analysis we conducted indicated that Bet concentrations in plasma and in milk, either alone or in combination with PCho, were most strongly associated with Cho net portal flux for cows receiving ADC. The developed relationships were based only on one data set, and more data will be needed to increase the robustness of the prediction equations. However, the low predictive error, when using RPC treatments to validate the equations, suggests that the current equations can provide a reasonable Cho bioavailability prediction for future studies with RPC supplementation. The constant CC delivery with $\mathrm{ADC}$ and frequent blood sampling may have increased the possibility of observing an association for arterial Bet and Cho with portal-absorbed Cho. Providing CC in a single meal increased blood concentrations of Cho and Bet for a limited period in humans, $<4$ and $<8$ h, respectively (Hirsch et al., 1978; Atkinson et al., 2008). Therefore, concentrations of milk Bet, alone or in combination with milk PCho, may be a more reliable marker for choline bioavailability in dairy cattle studies using dietary supplements of choline.

Overall, our results showed a linear increase in net Cho absorption with an increasing dose of ADC, and this resulted in increases in Cho and Bet concentrations in arterial plasma and milk. The net Cho absorption with RPC was low relative to ADC (13\%), which was similar to the relative difference observed in the concentrations and yields of milk Cho and Bet between the 2 choline sources (averaged 21\%). Previous markers used for choline bioavailability, such as total choline in milk, are not the most suitable biomarkers for assessing choline supply. Plasma and milk concentrations of Bet, alone or in combination with PCho, were found to be the most suitable markers of choline bioavailability in lactating dairy cows.

\section{ACKNOWLEDGMENTS}

The experiment was partially funded by Balchem Corporation (New Hampton, NY). The University of Tennessee (Knoxville) Biological and Small Molecule Mass Spectrometry Core performed the HILC-MS/MS analyses, which operate with support from the Office of Research and Engagement. The authors are grateful to Chantal Bolduc and Matthew Suitor for animal care, and Chrystiane Plante, Mario Leonard, and Véronique Roy for technical assistance (all from Agriculture and Agri-Food Canada, Sherbrooke, Québec, Canada).

\section{REFERENCES}

Ammerman, C. B., D. H. Baker, and A. J. Lewis. 1995. Bioavailability of Nutrients for Animals: Amino Acids, Minerals, and Vitamins. Academic Press, London, UK.

Artegoitia, V. M., J. L. Middleton, F. M. Harte, S. R. Campagna, and M. J. de Veth. 2014. Choline and choline metabolite patterns and associations in blood and milk during lactation in dairy cows. PLoS One 9:e103412.

Atkinson, W., J. Elmslie, M. Lever, S. T. Chambers, and P. M. George. 2008. Dietary and supplementary betaine: acute effects on plasma betaine and homocysteine concentrations under standard and postmethionine load conditions in healthy male subjects. Am. J. Clin. Nutr. 87:577-585.

Bligh, E. G., and W. J. Dyer. 1959. A rapid method of total lipid extraction and purification. Can. J. Biochem. Physiol. 37:911-917.

Bobe, G., J. W. Young, and D. C. Beitz. 2004. Invited review: Pathology, etiology, prevention, and treatment of fatty liver in dairy cows. J. Dairy Sci. 87:3105-3124.

Budowski, P., I. Kafri, and D. Sklan. 1977. Utilization of choline from crude soybean lecithin by chicks 2. Absorption measurements. Poult. Sci. 56:754-757.

Canadian Council on Animal Care (CCAC). 2009. Guide to the Care and Use of Experimental Animals. 2nd ed. Vol. 1. E. D. Rolfert, B. M. Cross, and A. A. McWilliam, ed. Canadian Council on Animal Care, Ottawa, Ontario, Canada.

Cheng, W.-L., M. Q. Holmes-McNary, M.-H. Mar, E. L. Lien, and S. H. Zeisel. 1996. Bioavailability of choline and choline esters from milk in rat pups. J. Nutr. Biochem. 7:457-464.

Combs, G. F., Jr. 2012. The Vitamins: Fundamental Aspects in Nutriton and Health. 4th ed. Academic Press, London, UK.

Deuchler, K. N., L. S. Piperova, and R. A. Erdman. 1998. Milk choline secretion as an indirect indicator of postruminal choline supply. J. Dairy Sci. 81:238-242.

Eklund, M., E. Bauer, J. Wamatu, and R. Mosenthin. 2005. Potential nutritional and physiological functions of betaine in livestock. Nutr. Res. Rev. 18:31-48.

Elek, P., T. Gaál, and F. Husvéth. 2013. Influence of rumen-protected choline on liver composition and blood variables indicating energy balance in periparturient dairy cows. Acta Vet. Hung. 61:59-70.

Elek, P., and F. Husvéth. 2007. In situ evaluation of the ruminal stability of different choline products. Hung. J. Anim. Prod. 56:589-595.

Fischer, L. M., K. A. da Costa, J. Galanko, W. Sha, B. Stephenson, J. Vick, and S. H. Zeisel. 2010. Choline intake and genetic polymorphisms influence choline metabolite concentrations in human breast milk and plasma. Am. J. Clin. Nutr. 92:336-346.

Flower, R. J., R. J. Pollitt, P. A. Sanford, and D. H. Smyth. 1972. Metabolism and transfer of choline in hamster small intestine. J. Physiol. 226:473-489.

Goselink, R. M. A., J. van Baal, H. C. A. Widjaja, R. A. Dekker, R. L. G. Zom, M. J. de Veth, and A. M. van Vuuren. 2013. Impact of rumen-protected choline supplementation on liver and adipose gene expression during the transition period in dairy cattle. J. Dairy Sci. 96:1102-1116.

Gressley, T. F., S. M. Reynal, J. J. O. Colmenero, G. A. Broderick, and L. E. Armentano. 2006. Technical note: Development of a tool to insert abomasal infusion lines into dairy cows. J. Dairy Sci. 89:3965-3967.

Hartwell, J. R., M. J. Cevava, and S. S. Donkin. 2000. Impact of dietary rumen undegradable protein and rumen-protected choline on intake, prepartum liver triacylglyceride, plasma metabolites and milk production in transition dairy cows. J. Dairy Sci. 83:29072917.

Hirsch, M. J., J. H. Growdon, and R. W. Wurtman. 1978. Relations between dietary choline and lecithin intake, serum choline levels, and various metabolic indices. Metabolism 27:953-960.

Huntington, G. B., C. K. Reynolds, and B. H. Stroud. 1989. Techniques for measuring blood flow in splanchnic tissues of cattle. J. Dairy Sci. 72:1583-1595. 
Jiang, X., J. Yan, and M. A. Caudill. 2014. Choline. Pages 491-513 in Handbook of Vitamins. 5th ed. J. Zempleni, J. W. Suttie, J. F. Gregory, III, and P. J. Stover, ed. CRC Press, Boca Raton, FL.

Katz, M. L., and E. N. Bergman. 1969. A method for simultaneous cannulation of the major splanchnic blood vessels of the sheep. Am. J. Vet. Res. 30:655-661.

Kettunen, H., S. Peuranen, K. Tiihonen, and M. Saarinen. 2001. Intestinal uptake of betaine in vitro and the distribution of methyl groups from betaine, choline, and methionine in the body of broiler chicks. Comp. Biochem. Physiol. A Mol. Integr. Physiol. 128:269-278.

Lima, F. S., M. F. Sá Filho, L. F. Greco, and J. E. P. Santos. 2012. Effects of feeding rumen-protected choline on incidence of diseases and reproduction of dairy cows. Vet. J. 193:140-145.

Littell, R. C., P. R. Henry, A. J. Lewis, and C. B. Ammerman. 1997. Estimation of relative bioavailability of nutrients using SAS procedures. J. Anim. Sci. 75:2672-2683.

Littell, R. C., G. A. Milliken, W. W. Stroup, R. D. Wolfinger, and O. Schabenberger. 2006. SAS for Mixed Models, 2nd ed. SAS Publishing, Cary, NC.

Lobley, G. E., A. Connell, M. A. Lomax, D. S. Brown, E. Milne, A. G. Calder, and D. A. Farningham. 1995. Hepatic detoxification of ammonia in the ovine liver: Possible consequences for amino acid catabolism. Br. J. Nutr. 73:667-685.

March, B. E., and C. MacMillan. 1980. Choline concentration and availability in rapeseed meal. Poult. Sci. 59:611-615.

McCourt, C. L., T. L. Chandler, S. J. Bertics, B. A. Barton, and H. W. White. 2015. Supplementation of choline increases very low density lipoprotein export from bovine primary hepatocytes. J. Dairy Sci. 98(Suppl. 3):2.

NFACC. 2009. Code of Practice for the Care and Handling of Dairy Cattle. Dairy Farmers of Canada and National Farm Animal Care Council (NFACC), Ottawa, ON, Canada.

NRC. 2001. Nutrient Requirements of Dairy Cattle. 7th rev. ed. Natl. Acad. Press, Washington, DC.

OECD. 2004. OECD SIDS, Choline Chloride. Accessed Jul. 24, 2016 http://www.inchem.org/documents/sids/sids/67481.pdf.

Papas, A... and S. H. W. Wu.. 1997. Rumen-stable delivery systems. Adv. Drug Deliv. Rev. 28:323-334.
Phillips, M. M. 2012. Analytical approaches to determination of total choline in foods and dietary supplements. Anal. Bioanal. Chem. 403:2103-2112.

Piepenbrink, M. S., and T. R. Overton. 2003. Liver metabolism and production of cows fed increasing amounts of rumen-protected choline during the periparturient period. J. Dairy Sci. 86:1722-1733.

Pinotti, L., A. Baldi, I. Politis, R. Rebucci, L. Sangalli, and V. Dell'Orto. 2003. Rumen-protected choline administration to transition cows: Effects on milk production and vitamin E status. J. Vet. Med. A Physiol. Pathol. Clin. Med. 50:18-21.

Pinotti, L., A. Campagnoli, L. Sangalli, R. Rebucci, V. Dell'Orto, and A. Baldi. 2004. Metabolism in periparturient dairy cows fed rumen-protected choline. J. Anim. Feed Sci. 13(Suppl. 1):551-554.

Sharma, B. K., and R. A. Erdman. 1988. Effects of high amounts of dietary choline supplementation on duodenal flow and production responses of dairy cows. J. Dairy Sci. 71:2670-2676.

Sharma, B. K., and R. A. Erdman. 1989a. Effects of dietary and abomasally infused choline on milk production responses of lactating dairy cows. J. Nutr. 119:248-254.

Sharma, B. K. and R. A. Erdman. 1989b. In vitro degradation of choline from selected foodstuffs and choline supplements. J. Dairy Sci. 72:2772-2776.

Sheard, N. F., and S. H. Zeisel. 1986. An in vitro study of choline uptake by intestine from neonatal adult rats. Pediatr. Res. 20:768772.

Zahra, L. C., T. F. Duffield, K. E. Leslie, T. R. Overton, D. Putnam, and S. J. LeBlanc. 2006. Effects of rumen-protected choline and monensin on milk production and metabolism of periparturient dairy cows. J. Dairy Sci. 89:4808-4818.

Zhao, Y.-Y., Y. Xiong, and J. M. Curtis. 2011. Measurement of phospholipids by hydrophilic interaction liquid chromatography coupled to tandem mass spectrometry: The determination of choline containing compounds in foods. J. Chromatogr. A. 1218:5470-5479.

Zom, R. L. G., J. Van Baal, R. M. A. Goselink, J. A. Bakker, M. J. de Veth, and A. M. Van Vuuren. 2011. Effect of rumen-protected choline on performance, blood metabolites, and hepatic triacylglycerols of periparturient dairy cattle. J. Dairy Sci. 94:4016-4027. 